\title{
The Occurrence of Vitamin $\mathrm{G}$ in Foods
}

\author{
By M. van Eekelen, Central Institute for Nutrition Research T.N.O., \\ Utrecht, The Netherlands
}

\section{Methods of measurement}

Quantitative determinations of the vitamin C content of foods could only be done after 1932 when the vitamin was isolated in the crystalline state. In 1930-2 Tillmans and co-workers (Tillmans, I930; Tillmans, Hirsch \& Dick, I932; Tillmans, Hirsch \& Hirsch, 1932; Tillmans, Hirsch \& Jackisch, r932a,b; Tillmans, Hirsch \& Siebert, r 932) introduced a simple chemical method for determining vitamin $\mathrm{C}$ and then progress in our knowledge about the distribution and behaviour of the vitamin became rapid.

This chemical method, the titration of the reduced ascorbic acid with the redox dye 2:6 dichlorophenolindophenol, has up to the present day continued to be the most usual method, albeit with a number of improvements enhancing the accuracy and specificity.

Besides this method, the Roe \& Kuether (1943) method based on the formation of the double-hydrazone of dehydroascorbic acid with 2:4 dinitrophenylhydrazine has become more generally known. This method is useful especially for the determination of small quantities of ascorbic acid, e.g. in blood.

In the very many investigations on the vitamin $\mathrm{C}$ content of foods it has not always been sufficiently realized that a thoughtless application of the titrimetric method may cause great analytical errors, which, in some instances, have led to strange conclusions. What are we to think of the conclusion that was once drawn that potatoes contain no vitamin $\mathrm{C}$, while it was known from animal experiments and from experience gained in human dietetics that potatoes have an antiscorbutic effect and, indeed, that scurvy as a national disease in our countries disappeared when, in the course of the eighteenth century, potatoes had become generally adopted as a common food? What are we to think of the investigations in which it was shown that cooked vegetables had a higher amount of titratable ascorbic acid than raw ones and it was concluded that in raw vegetables a part of the ascorbic acid was bound in a non-titratable form from which it could be liberated by heating or by treatment with strong acid? And finally, what are we to think of the estimation of a large quantity of vitamin $\mathrm{C}$ in roasted coffee beans or of the finding of large quantities of vitamin $\mathrm{C}$, in the urine of persons the composition of whose food made this finding highly improbable?

These conclusions would never have been drawn had there been a more critical attitude towards analytical work in general and towards the analysis of vitamin $\mathrm{C}$ in particular.

In determining vitamin $\mathrm{C}$ titrimetrically one has to bear in mind that besides ascorbic acid the reversibly oxidized form of the vitamin, dehydroascorbic acid, 
may be present. This biologically active but non-titratable substance may already occur in the food or may be formed during analysis. Furthermore, some products (especially prepared foods) may contain substances that are inactive as antiscorbutics but have the same reducing properties as ascorbic acid.

In fresh vegetables and fruits almost no dehydroascorbic acid occurs. It may, however, arise during extraction, when the process is unduly prolonged and especially if oxidases are present. If the oxidases are not eliminated, e.g. by carrying out the extraction with sufficiently strong metaphosphoric acid, too little or even no ascorbic acid will be found, and then it may be concluded that combined ascorbic acid is present, which is liberated by heating or by treatment with strong acid, whereas actually by this treatment only oxidases are destroyed.

When in a food, e.g. in prepared vegetables or in fruit salads, dehydroascorbic acid does occur, this can be titrated, as Tillmans (Tillmans, 1930; Tillmans, Hirsch \& Dick, 1932; Tillmans, Hirsch \& Hirsch, 1932; Tillmans, Hirsch \& Jackisch, I932a,b; Tillmans, Hirsch \& Siebert, I932) has already demonstrated, after reduction with hydrogen sulphide in weak acid medium.

Unspecific reducing substances are not found in measurable quantities in fresh vegetables or fruits. They may, however, occur in processed foods. Iron, tin, reducing sulphur compounds, gluco-reductones may interfere. Especially difficult to distinguish from ascorbic acid titrimetrically are the reductones in roasted foods, such as coffee beans, bread crust and biscuits.

Many methods have been recommended in the course of time to eliminate these interfering substances. I will mention only the simple titration of the interfering substances as suggested by Levy (1943) in $20 \%$ hydrochloric acid, in which medium ascorbic acid does not reduce the dye. This method ought, in my opinion at least, to be applied in every titrimetrical estimation of vitamin $\mathrm{C}$ in foods.

Other methods for the determination of ascorbic acid, such as the phenylhydrazine method of Roe \& Oesterling (1944) or the polarographic method have, just as the titrimetric one, the disadvantage that other substances may interferefor instance diketogulonic acid, which may arise from dehydroascorbic acid, reacts also with $2: 4$ dinitrophenylhydrazine.

\section{Occurrence of vitamin $C$ in various vegetable foods, both fresh and prepared}

The main sources of vitamin $\mathrm{C}$ are fruits, vegetables and potatoes (I mention potatoes separately, because in some countries potatoes are not considered as a vegetable). Seeds, such as dry cereals and pulses and the products made from these, such as flour and bread, do not contain ascorbic acid.

The amount of vitamin $\mathrm{C}$ in various vegetables and fruits varies considerably. While apples, pears, melons, peaches, bananas and grapes contain $3^{-10} \mathrm{mg} / 100 \mathrm{~g}$, tomatoes have $15 \mathrm{mg}$, oranges, lemons, grape-fruit, strawberries 40 up to $80 \mathrm{mg}$, black currants $140 \mathrm{mg}$ and rose-hips more than $500 \mathrm{mg} / \mathrm{roOg}$; the hips of Rosa oxyodon contain even $7000 \mathrm{mg} / \mathrm{I} 00 \mathrm{~g}$.

Of the raw vegetables, carrots, beet, onions, endive, lettuce and salsify contain 
a relatively small amount, $5^{-1} 5 \mathrm{mg} / \mathrm{r} 00 \mathrm{~g}$; the various varieties of cabbage, spinach, asparagus contain more, from 30 to $90 \mathrm{mg} / \mathrm{ro0} \mathrm{g}$.

It is obviously difficult, for instance in a food composition table, to give the value for the amount of ascorbic acid in a given foodstuff, since many factors determine this value. In the first place the amount in different parts of the plant or fruit may vary considerably. Bacharach (Bacharach, Cook \& Smith, 1935) has shown that orange peel contains per gram from three to six times more than the juice. Miss Olliver (1938) found that asparagus tips contain per gram more than the green stems and the latter more than the white stems, the concentrations being in the relatively high proportions of approximately $6: 3: 1$. The green outer leaves of cabbages contain from two to three times more than the yellow inner leaves.

Moreover, the concentration in plants depends on genetic factors, manuring, exposure to light, degree of ripeness, time of harvesting, time and conditions of storage. Ripe fruits contain more than unripe; early-lifted potatoes twice as much as those dug later. In vegetables vitamin $\mathrm{C}$ is rapidly lost on storage at room temperature, whereas fruits retain their vitamin $\mathrm{C}$ comparatively well. In old stored potatoes the loss is about $60-80 \%$.

The method of preparation of the food has perhaps a still greater influence. In boiling greens a certain amount of vitamin is always lost both by extraction in the water and by oxidation, possibly under the influence of oxidases. Hence it is of importance in cooking to bring the vegetables up to boiling temperature quickly, to boil them in a minimum of time and with as little water as possible. The amount of ascorbic acid in potatoes changes but slightly in cooking, provided the potatoes are not boiled too far, but great loss is caused (by oxidation) if the hot cooked potatoes are mashed.

Losses in vitamin $\mathrm{C}$ may also occur in industrial processing of vegetables and fruits. Here, too, the magnitude of the losses depends on the way the products are handled. In the process of canning, drying and freezing, the preliminary blanching causes most of the loss, but this is less than in home cooking, because usually less water is used. During sterilization and storage of the cans, there is little destruction of the vitamin. Moreover the factories must use freshly picked material, whereas the housewife often has to rely on shop-stored vegetables. Of great importance is the metal of the machinery with which the food comes into contact. If this contains copper, it will have a most destructive effect on the vitamin. For instance, the ascorbic acid concentration in sterilized tomato juice may be thus reduced to nothing by oxidation!

In a well-equipped factory that pays attention to the preservation of vitamin $\mathrm{C}$ in its products the losses are not too great. 'The question is, however, what the housewife does with the processed food before it appears on the table. Canned foods need only to be warmed up and the loss of vitamin will thereby be kept within limits. Dried vegetables and potatoes are usually soaked a long time in water, during which nearly all the vitamin is leached out and is thrown away with the water. It is, however, not necessary to do so. Dried vegetables can be prepared in only as much water as they can absorb and the adhering water is sufficient to boil them in. 


\section{Vitamin $C$ in foods of animal origin}

Eggs, cheese, edible oils and fats contain no vitamin $\mathrm{C}$; meat and milk only about $2 \mathrm{mg} / \mathrm{I} 00 \mathrm{~g}$; some animal organs such as kidneys and liver somewhat more, 14 and $25 \mathrm{mg} / \mathrm{ro0} \mathrm{g}$ respectively. The vitamin $\mathrm{C}$ content of cow's milk deserves our special attention, because for many babies cow's milk is the only source of ascorbic acid. Fresh, raw milk has a constant ascorbic-acid content of about $2 \mathrm{mg} / 100 \mathrm{ml}$. After boiling as well as after pasteurization this drops to about $\mathrm{I}^{\circ} 5 \mathrm{mg}$, so that babies fed on this milk as the only source of vitamin C get about $7 \mathrm{mg}$ daily; that is enough to protect them against scurvy.

It should be mentioned that breast-fed babies usually get more vitamin $C$, though the vitamin $\mathrm{C}$ content of human milk depends on the amount of vitamin $\mathrm{C}$ in the diet of the mother. In Utrecht we estimated the vitamin $\mathrm{C}$ concentration of human milk during the year. We found in May (i.e. the month in which least vitamin $\mathrm{C}$ is taken by the mother) from 0.8 to $3.5 \mathrm{mg} / 100 \mathrm{ml}$. (average $\mathrm{I} \cdot 8$ $\mathrm{mg} / \mathrm{I} 00 \mathrm{ml}$ ), in August (when most vitamin $\mathrm{C}$ is eaten) from $4 . \mathrm{I}$ to $6.8 \mathrm{mg} / \mathrm{I} 00$ $\mathrm{ml}$. (average $5.5 \mathrm{mg} / 100 \mathrm{ml}$.). This means that breast-fed babies get amounts varying from 4 to about $34 \mathrm{mg}$ daily (van Eekelen, unpublished).

If cow's milk undergoes treatment other than processes of boiling or pasteurization the vitamin $\mathrm{C}$ content may diminish considerably. Copper and also light catalyse the oxidation of ascorbic acid into dehydroascorbic acid, which, in milk, is very rapidly destroyed. Repeated heating or sterilizing causes additional losses.

During the war years and also during the first few years after the war the result of abnormal treatment of the milk could be noticed in The Netherlands. The milk supplied from the northern and eastern part of the country to the cities in the western part was mostly pasteurized twice, once in the district where it was produced and a second time in the city where it was consumed. Moreover, the milk was standardized at a fat percentage of $2 \cdot 5$, usually, at any rate during winter, by adding skim-milk powder and water. On delivery to the consumer, this product had a vitamin concentration of $0.2-0.9 \mathrm{mg} / 100 \mathrm{ml}$. At home, of course, it was boiled again and before the baby got the bottle it was warmed up once more. Is it surprizing that after all this there was no vitamin $\mathrm{C}$ left? The consequence was a rapid increase of cases of infantile scurvy. For instance the number of cases admitted annually into the children's hospital in Utrecht increased from none to two before the war to twenty-nine in 1947 . Under these circumstances the demand for the administration of extra vitamin $\mathrm{C}$ as tablets or fruit juice was well justified.

\section{The daily human requirements for vitamin $C$}

Estimates of human need differ widely, from about $10 \mathrm{mg}$ as a minimum daily requirement up to $100 \mathrm{mg}$ as an optimum dose. If $\mathrm{IO}$, or let us say $20 \mathrm{mg}$ daily are sufficient, only an exceptionally unbalanced diet would lead to scurvy. A normal helping of potatoes, vegetables or fruit, of any kind and no matter how prepared, 
would provide enough vitamin $\mathrm{C}$. This opinion is supported by the observed incidence of scurvy. In normal times we see in The Netherlands but sporadic cases: in babies fed on wrongly treated milk and in old widowers who, having lost their wives, no longer get any hot meals and are satisfied with such foods as bread and butter, cheese and bacon. However, if it is thought that a dose of roo $\mathrm{mg}$ daily is beneficial for health, it would be found difficult to procure food in these countries every season of the year containing this quantity. We should fully realize what foods are rich in vitamin $\mathrm{C}$ and do our utmost to prevent any loss in the preparation of foods. For this purpose an extensive propaganda campaign will be essential.

\section{REFERENCES}

Bacharach, A. L., Cook, P. M. \& Smith, E. L. (1935). Biochem. F. 28, 1038. Levy, L. F. (1943). Biochem. F. 37, 713.

Olliver, M. (1938). Analyst, 63, 2.

Roe, J. H. \& Kuether, C. A. (1943). F. biol. Chem. 147, 399.

Roe, J. H. \& Oesterling, H. J. (1944). F. biol. Chem. I52, 51 I.

Tillmans, J. (1 930). Z. Untersuch. Lebensmitt. 6o, 34.

'Tillmans, J., Hirsch, P. \& Dick, H. (1932). Z. Untersuch. Lebensmitt. 63, 267.

Tillmans, J., Hirsch, P. \& Hirsch, W. (1932). Z. Untersuch. Lebensmitt. 63, I.

Tillmans, J., Hirsch, P. \& Jackisch, J. (1932a). Z. Untersuch. Lebensmitt. 63, 241.

'Tillmans, J., Hirsch, P. \& Jackisch, J. (1932b). Z. Untersuch. Lebensmitt. 63, 276.

'Tillmans, J., Hirsch, P. \& Siebert, F. (1932). Z. Untersuch. Lebensmitt. 63, 2 I. 